\title{
Languagépapersin
}

Paper 1.

\section{Language and Movement in Space}

\author{
Jan Blommaert \\ University of Jyväskylä and University of Tilburg \\ Jie Kathy Dong \\ University of Tilburg
}

Handbook of Language and Space, Auer (ed.). Draft, version 2007-08-06.

Contact: J.Blommaert@ioe.ac.uk

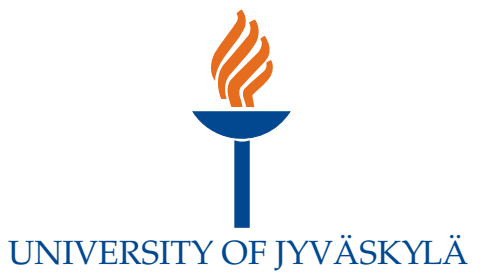




\section{Two paradigms}

Commenting on the way in which globalization processes are currently represented, Immanuel Wallerstein cautions:

"If we look at globalization and terrorism as phenomena that are defined in limited time and scope, we tend to arrive at conclusions that are as ephemeral as the newspapers. By and large, we are not then able to understand the meaning of these phenomena, their origins, their trajectory, and most importantly where they fit in the larger scheme of things." (Wallerstein 2004: ix)

Part of the problem, Wallerstein adds, is "that we have studied these phenomena in separate boxes to which we have given special names": the social sciences as currently constituted. He thus outlines the challenge of coming to terms with contemporary globalization processes: to understand them by means of theoretical frames that transcend the currently established ones. This means that we all have to move to more holistic objects of analysis, and that we continually have to critically re-examine the conceptual and methodological toolkits we use.

The current wave of globalization is best understood as a development within globalization. The fact that we now use the term 'globalization' to describe the current developments should not trick us into believing that what we observe is fundamentally new. We just have a better word for it - a word that triggers a range of metaphors and images of intensified flows and movements across space and time, of people, goods, messages, objects. These flows have been there for quite a while; we are now in a position to examine them more accurately. ${ }^{1}$ The advent of the internet has given many of us a sense that we live in an age of 
revolutionary change. It is good to remember that the development of the telegraph, telephone, radio and television caused the same buzz among contemporary observers. And what to think of the development, centuries earlier, of book printing ${ }^{2}$ These earlier developments, too, had an impact on the way in which people used and circulated language, and on the way in which language varieties penetrated societies. Only, contemporary observers sought to understand linguistic phenomena very much with reference to language, not to society, and very much from within a frame in which the temporal and spatial conditions of occurrence of language were seen as accidental and not very important. The descriptive and comparative tradition of the late $19^{\text {th }}$ and early $20^{\text {th }}$ century was an 'artefactual' tradition, in which languages were connected to timeless peoples, who were topographically plotted on a particular area of distribution (Irvine 2001; Blommaert 2006). When time was concerned, linguistics tended to use genealogical models; when space was concerned, it tended to use horizontal models of space, expressed in stock metaphors such as 'spread' or 'distribution' of languages or of linguistic features.

Modern sociolinguistics drew this artefactualised image of language into real time and space. Studies of language variation focused strongly on diffusion - the spread of linguistic variables over a horizontal space, as in the work of Trudgill, Labov and others (see Britain \& Cheshire (2003). The conceptual development of space and time in such studies is superficial: there is attention for generational transmission (time) and distribution of variables in one locality or across localities such as cities, regions or countries (space). Labov's famous studies of New York City (1966) and of Martha's Vineyard (Labov 1972) are classics in this trend. Contact linguistics, in the meantime, focused on the sociolinguistic and linguistic patterns resulting from migration (Clyne 2003), and patterns of multilingualism resulting from migrations also drew the attention of scholars (Extra \& Verhoeven 1998). One widespread problem with such studies is that the people whose language repertoires are studied, even if 
they are migrants, are 'fixed', so to speak, in space and time. The phenomenology of migration and diaspora became an object of theoretical elaboration in cultural studies, sociology and anthropology and surely in the context of recent globalization processes, notions such as transcultural flows, transidiomaticity and deterritorialisation made their way into mainstream social science (Appadurai 1996; see also Jacquemet 2005). We now see that the mobility of people also involves the mobility of linguistic and sociolinguistic resources, that 'sedentary' patterns of language use are complemented by 'translocal' forms of language use, and that the combination of both often accounts for unexpected sociolinguistic effects. The possibility of frequent electronic contact with the country of origin, for instance, can generate new forms of language innovation (and thus contribute to language maintenance) in diasporic communities (REF); small and marginal languages can, in the context of tourism, acquire new and unexpected forms of prestige (Heller 2003); popular culture such as Hip Hop or Reggae can be a vehicle for the worldwide dissemination of particular language forms (Pennycook 2007), including new forms of literacy and message design (Kress and van Leeuwen 1996). All of these dimensions of mobility still collapse in concrete spaces where actual people live and interact with one another; the structure of people's repertoires and the patterns of multilingual language use, however, become less predictable and significantly more complex (Blommaert, Collins \& Slembrouck 2005a, 2005b; Collins 2007).

The upshot of these developments is that we see two paradigms develop, one established and one emerging. The established paradigm is the sociolinguistics of distribution as sketched above, in which movement of language resources is seen as movement in a horizontal and stable space; within such spaces, vertical stratification can occur along lines of class, gender, age, social status etc. The object of study, however, remains a 'snapshot', in which things are in place, so to speak. The second paradigm can be called a sociolinguistics of mobility, and it focuses not on language-in-place but on language-in-motion, with various 
spatiotemporal frames interacting with one another. Such spatiotemporal frames have been described as 'scales', and the assumption is that in an age of globalization, language patterns must be understood as patterns that are organized on different, layered scale-levels (Blommaert 2005, 2007; Collins 2007). Access to and control over scales is unevenly distributed, it is a matter of power and inequality - as becomes clear when we consider typical resources for access to higher (i.e. non-local and non-situationally specific) scales such as a sophisticated standard language variety or advanced multimodal and multilingual literacy skills.

This second paradigm, of course, faces the challenge of incorporating a more profound theoretical understanding of space. Space, here, is metaphorically seen as vertical space, as layered and stratified space. Every horizontal space (e.g. a neighbourhood, a region, a country...) is also a vertical space, in which all sorts of socially, culturally and politically salient distinctions occur. Such distinctions, as we shall see later, are indexical distinctions: distinctions that project minute linguistic differences onto stratified patterns of social, cultural and political value-attribution; they convert linguistic differences into social inequalities and thus represent the 'normative' dimensions of situated language use (Silverstein 2006; Agha 2007). The stratified and ordered nature of such indexical processes we can call, by analogy with Foucault's 'order of discourse', orders of indexicality (Blommaert 2005), and every horizontal space is filled with such orders of indexicality - with normative complexes that organise distinctions between 'good', 'normal', 'appropriate', 'acceptable' language use and 'deviant', 'abnormal' etc. language use. Orders of indexicality define the dominant lines for senses of belonging, for identities and roles in society (and thus underlie what Goffman called the 'interaction order' - which is an indexical order; Silverstein 2003; Agha 2007; Collins \& Slembrouck 2007). 
Movement of people across space is therefore never a move across empty spaces. The spaces are always someone's space, and they are filled with norms, expectations, conceptions of what counts as proper and normal (indexical) language use and what does not counts as such. Mobility, sociolinguistically speaking, is therefore a trajectory through different stratified, controlled and monitored spaces in which language 'gives you away'. Big and small differences in language use locate the speaker in particular indexical - that is, identity and role - ascriptive categories, and as we learned from John Gumperz' work (e.g. 1982), this is rarely inconsequential. Let us now turn to such patterns of mobility.

\section{Globalization, super-diversity and multilingualism}

\subsection{Super-diversity}

As mentioned above, the current globalization processes are best seen as part of longer, wider and deeper globalization processes, in which they represent a particular stage of development. That development is real, however, and especially the changes in economic and technological infrastructure have affected whatever we currently understand by mobility. Migration was long seen as people emigrating and immigrating - that is, a change in the spatial organization of one's life in an enduring way. People left their country and settled in another. In that new country, they lived separated from their country of origin, perhaps (but not necessarily) in ethnic communities. They took their languages and other cultural belongings with them, but the separation from the land of origin and the permanent nature of migration was likely to bring pressure to accommodate to the host society. A tradition of study emerged in Western host societies on such relatively isolated, stable and residential immigrant groups, often also consisting of large communities from the same country or even region of origin: Turks in 
Germany, Algerians and West-Africans in France, Caribbean and East- or South-Asian people in Britain. ${ }^{3}$

The 1990s brought a change in the nature and profile of migration to Western host societies, and Steven Vertovec (2006: 1) summarizes that process as follows:

"Over the past ten years, the nature of immigration to Britain has brought with it a transformative 'diversification of diversity' not just in terms of ethnicities and countries of origin, but also with respect to a variety of significant variables that affect where, how, and with whom people live".

These variables, Vertovec continues,

"include a differentiation in immigration statuses and their concomitant entitlements and restrictions of rights, labour market experiences, gender and age profiles, spatial factors, and local area responses by service providers and residents. (...) The interplay of these factors is what is meant here, in summary fashion, by the notion of 'superdiversity"”.

The new migrants typically settle in older immigrant neighbourhoods, which thus develop into a layered immigrant space, where resident ('old') immigrants often rent spaces to newer, more temporary or transient groups, and where new segments of the labour market are developed. Many of the new immigrants live in economically and legally precarious circumstances, and many of them are strongly dependent upon informal employment and solidarity networks such as churches (Blommaert et al 2005; Blommaert, Collins \& Slembrouck 2005a, 2005b). The extreme linguistic diversity in such neighbourhoods 
generates complex multilingual repertoires in which often several (fragments of) 'migrant' languages and lingua francae are combined. ${ }^{4}$ And such neighbourhoods often display a density of mediating institutions such as welfare and employment offices, as well as night shops and - significantly - telephone shops where international calls and internet access are offered at bargain prices.

Super-diversity poses descriptive as well as theoretical challenges. Descriptively, these globalised neighbourhoods appear chaotic, and common assumptions about the national, regional, ethnic, cultural or linguistic status of the inhabitants often prove to be useless. The presuppositions of common integration policies - that immigrants were known, and that they would have a shared language and culture - can no longer be upheld. In addition, the telephone shops show that even if new migrants reside in one particular place, they are capable of maintaining intensive contacts with networks elsewhere, including often their countries of origin. A burgeoning network of satellite and internet providers also allows them to follow (and be involved in) events in their country of origin, and to consume its media and cultural products. Their spatial organisation, consequently, is local as well as translocal, real as well as virtual - and all of this has effects on the structure and development of language repertoires and patterns of language use. Theoretically, this stretches the limits of existing frameworks for analysing and understanding multilingualism and the dynamics of language change. We can illustrate the complexity of these phenomena and theoretical issues by looking at a globalised neighbourhood in Berchem, Antwerp.

\subsection{Multilingual repertoires and super-diversity}

The repertoires of new migrants often appear to be 'truncated' (Blommaert, Collins \& Slembrouck 2005a): highly specific 'bits' of language and literacy varieties combine in a 
repertoire that reflects the fragmented and highly diverse life-trajectories and environments of such people. Thus, recent West-African immigrants in Berchem, Antwerp can combine one or more African languages with a heavily accented vernacular variety of West-African English, which can be used with some interlocutors in the neighbourhood, and would be the medium of communication during weekly worship sessions in a new evangelical church in the neighbourhood (figure 1). English, however, is not part of the repertoire of most other immigrants in the neighbourhood. Most of the shops, for instance, would be owned by Turkish or Moroccan people, who would often use vernacular forms of German or French as a lingua franca. Thus, when a Nigerian woman goes to buy bread in a Turkish-owned bakery, the code for conducting the transaction would, for both, be a strongly accented and very limited variety of local vernacular Dutch, mixed with some English, respectively German words. In the phone shops, vernacular English would have slightly more currency, because the phone shops would typically be run by people from India or Pakistan. Note, however, that the particular varieties of English spoken in such transactions would be very different: none would be 'standard', each variety would reflect informal patterns of acquisition and an uneasiness in use.

The Dutch used in the bakery is a minimal, informally acquired small 'bit' of language, a specialised language skill that has its limits. It is insufficient to navigate institutional encounters: bureaucratic procedures are in standard and literate varieties of Dutch, typically varieties that result from formal acquisition efforts. Thus, when the Nigerian woman goes to her daughter's school for consultation on the child's progress, she would have to revert to her vernacular English. This would then be met by a heavily accented BelgianFlemish variety of English from the teachers, and the interaction is typically less than smooth. The medium of communication between mother and child would be a mixed code, often blending unevenly distributed chunks of Dutch and English. The child, of course, would have 
access to more elaborate varieties of standard and local vernacular Dutch and would often have to assist the mother and the teacher in accomplishing the communication tasks. This, importantly, points towards another feature of language in such neighbourhoods: the fact that they often involve collaborative work. People would call on others, or others would volunteer, to translate and assist in communication. This is not only the case for tasks that involve literacy; it can also be noticed in face-to-face encounters. People very often pool their competences and skills in language when they have to accomplish demanding communication tasks.

At home, the Nigerian family would have access to television, and the choice would go to English-medium channels such as BBC World or MTV, with an occasional foray, often initiated by the children, into Dutch-medium children's programmes. There would be a very low level of consumption of local printed mass-media, and access to printed sources from Nigeria would be restricted. At the same time, telephone contacts would be maintained with people back home and fellow migrants from the same region of origin, now living in Brussels, London or Paris. Occasionally, there would be mutual visits during which the African regional language can be the medium of communication among adults, while the children revert to vernacular forms of English to interact with each other. Their exposure to education environments in which different languages are the medium of instruction - Dutch and French, for instance - precludes the use of any other language.

Thus we see very fragmented and 'incomplete' - 'truncated' - language repertoires, most of which consists of spoken, vernacular and accented varieties of different languages, with an overlay of differentially developed literacy skills in one or some languages (depending on the level of literacy at the time of migration). We also see how many communication tasks are accomplished collaboratively, by combining the resources and skills of several people. The particular patterns of such repertoires are difficult to establish in detail 
- here is the descriptive challenge. The sociolinguistic world of these people is strictly local (the neighbourhood) as well as widely translocal (the network of fellow migrants elsewhere, the communication with people back home, the media). And internally, we see differentiation in language repertoires, in which adults have different repertoires than children, and fellow migrants from the same region now living elsewhere have different repertoires as well.

The local environment of these people is abundantly multilingual. Since Nigerians are a very small minority, their languages are invisible in the public space. The older, resident communities - Turks and Moroccans - do publicly display the formal, literate aspects of their multilingualism (figure 2). We see Arabic and Turkish displayed in shops and on posters announcing cultural or political events. Such public language displays can index the size and the degree of solidification of particular immigrant communities. Thus, Albanian posters have recently begun to appear, indicating the existence of a well-organised and resident Albanian migrant community in Belgium (figure 3). Groups that have not yet achieved that level of stability and visibility revert to highly unstable forms of written language, mixing English and Dutch and betraying vernacular pronunciation of words, as the display of tariffs in phone shops illustrate (figure 4). They are also addressed by fully globalised signs in Standard English, advertising products that cater to the specific needs of recent and economically vulnerable immigrants, such as money transfer operations (figure 5).

The uneven distribution of language resources, degrees of public legitimacy of languages, and of patterns of access to language resources, becomes clear when we consider examples such as figure 6, where we see how someone changed the name 'Clear Channel' to 'Liar Channel' on a billboard. This is a playful language act, revealing advanced competence in English and in literacy, as well as a particular critical political stance. When we compare figure 6 with figure 4, we see how strongly the levels of literacy and command of language varieties differ within one community. The reason is the particular social and cultural mix of 
the neighbourhood. The neighbourhood has of late also seen an influx of educated, middleclass native Belgians, attracted by the affordable housing prices and (like the other immigrants) by the presence of a big railway station. These people, typically, have access to prestige varieties of language and prestige forms of multilingualism - Standard Dutch and Standard English. Thus, highly advanced multilingual repertoires can be displayed alongside very incomplete ones, and the general picture is one of extreme mixedness. It is hard to identify the 'dominant' language in the neighbourhood. Vernacular forms of Dutch would probably have the widest local currency; at the same time, various languages point inwards as well as outwards, to local communities and small networks in the neighbourhood as well as to translocal and transnational networks that have their 'hub' in the neighbourhood. Languages and language varieties operate and have validity at particular scale levels, from the strictly local to the strictly global, with all sorts of intermediate scale-levels in between. In our example, the weekly worship session gathers several hundreds of people and so creates a translocal, but locally anchored, scale-level. And the occasional visits from and to fellow immigrants also creates a local-translocal scale level. Each time, elements of the repertoires will have to be mobilised, because the different criss-crossing scales answer to different orders of indexicality. A language variety that is good enough to perform adequately during the worship session is not necessarily good enough for buying bread in the bakery, or for talking to the schoolteacher.

\subsection{Stratified distribution}

If we now try to summarize some of the elements discussed so far, we see that a sociolinguistic analysis of such globalization phenomena cannot proceed on the basis of common notions of distribution. First, what is distributed is not easily defined, for we are 
never just talking about languages, but always about highly specific language resources (the 'little bits' of language we referred to earlier). Second, how these resources are distributed also requires a lexicon and imagery of considerable complexity, for there is no 'flat' distribution, no juxtaposition of particular resources. We see a range of densely layered, stratified distribution patterns, in which the particular specific language resources are deployed (and deployable) on particular scale-levels and not on others; what is valid in one situation is not valid in another. Some resources will allow mobility across situations and scale-levels. Prestige varieties of language, such as Standard Dutch, for instance would have currency across a wide variety of situations; the same goes for prestige and literate varieties of English, be it in a very different set of situations. These are high-mobile resources. Others think of the African languages spoken by our Nigerian subjects - have very little in the way of mobility potential. Their range is largely confined to the adults in the family and the wider network, and to some restricted use with the children. Outside these situations, these languages have no potential for use. Institutionally they are often not even recognized as languages. ${ }^{5}$

The key to understanding this complex pattern is what counts as language in particular contexts: what is ratified and recognised as a valid code for making oneself understood. The key is, in other words, the indexical value that particular linguistic resources have. In highly complex neighbourhoods such as the one we discussed here, complex and truncated repertoires can have such validity, at least to the extent that particular ingredients of the repertoires are mapped onto particular micro-environments, networks or situations. Migrants, consequently, are often confronted with situations in which the language and communicative requirements stretch their repertoires, and in which complex patterns of shifting and mixing occur. It is in such moments that we see delicate articulations of subject position that index migrant identities and life trajectories. Let us now examine such patterns. 


\section{Accents, shifting and micro-variation}

\subsection{Accent on a street corner}

Human trajectories leave traces in speech repertoires, and whenever people produce language, they produce complex packages of accents: various regional accents, social status accents, age accents and gender accents. Such accent packages index identities, and the organisation of such indexical work is non-random. In order to illustrate the complexities as well as the systematic nature of such work, we will look at an excerpt of a fieldwork interview recorded in a migrant neighbourhood in Beijing, China, in late 2006. China has known a massive internal migration over the last decade, from rural areas to the cities and the special economic regions, as an effect of the country's economic boom. In the multi-ethnic and multilingual context of China, this has involved a reordering of the sociolinguistic landscape of immigrant areas. While Standard Chinese - Putonghua - is known by an overwhelming majority of citizens, regional accents do occur, and as elsewhere, they are ordered hierarchically. Certain accents mark a metropolitan, sophisticated identity while others mark rural origins, low levels of education and marginal social-economic status.

In this excerpt, the fieldworker $(\mathrm{R})$ goes out in the morning to buy dumplings from a street corner dumpling seller $(\mathrm{X})$, whose origins lie in the South. The fieldworker has a Beijing accent, and during the interaction with the dumpling seller, a delicate play of topic, accent and identity develops.

[TRANSCRIPT HERE]

Translation 
\{traffic noise, people talk unintelligibly $\}$

1 X. *which ones* (of the steamed dumplings) would you like? \{weak slow voice, noticeably trying to pronounce in local Beijing accent

R. what kinds do you offer?

X. here we have...

$5 \quad \ldots$ \{conversations about the kinds of steamed dumplings he offers $\}$

R. you are doing a good business: so many people get their breakfast from you.

X. $\{$ laughing voice $\} *$ only* good in the morning; no one comes in the afternoon $\{$ still making efforts at mimicking Beijing accent \}.

R. the morning business is good enough. Have you put the shrimp one in (the bag)?

10 X. $\{$ nod with smile $\}$ that's a good one - we brought the shrimps from our home town.

R. seriously?! Where is it?

X. $\{$ proud, smile $\}$ they are shrimps from the Yangtze river...good shrimps $\{$ his voice is noticeably higher and faster, and with clearer southern accent $\}$

... \{conversations about how they brought the shrimps from that far away place

15 R. you speak good Putonghua, did you learn that from school?

X. *just so-so*. Some (customers) couldn't figure out what I said \{end with laughing voice, indicating this is a humble response

R. I found your Putonghua is really good, I have no problem understand you.

X. well, we learnt Putonghua in school. I studied up to high school \{ switches from a

20 noticeable southern accent to near-Putonghua\}.

*are you* a Beijing person? \{ smile, and switch to certain characteristics of Beijing accent\}

R. yeah, I am from here.

X. *from here* \{repeat in a low voice, still in a effort of producing Beijing accent $\}$

25 R. did you all use Putonghua in school?

X. we learnt (Putonghua in school) but also talk in our own dialect.

R. then how comes your Putonghua is so good \{smile $\}$ ?

X. I... I was here before s switch to his Beijing accent with a higher, dragging and jolly voice\}

$30 \quad$ R. Do you (always) understand what people speak here in Beijing?

X. usually I can, when people talk in their dialects, I can't \{ switches back to Putonghua .

R. = sure. I can't if they use dialects. 
$35 \mathbf{X} .=$ they use dialects when order steamed dumplings, for a few minutes I don't know what they are telling me \{end with laughing voice, amused

R. that's right; also there is very mixed, you can find people from everywhere (of the country), and many dialects...

We see in this brief, friendly and informal interaction a series of shifts that are hardly noticeable when we use 'language' as our only diacritic. The whole of the conversation is in Chinese; but different varieties of Chinese are used, and the use of these differences is not random. This becomes clear when we look at the distribution of regionally marked, accented utterances by $\mathrm{X}$. They start occurring from line 12 on, and stop occurring in line 31, each time in a mix with an approximated Beijing accent. The fragments prior and after that part are spoken in an approximate Beijing accent (lines 1-11) and a rather neutral variety of Putonghua (lines 32-38).

These shifts in accent are part of a bigger series of shifts in the conversation. The three units are topical as well. In the first unit (1-11), $\mathrm{R}$ and $\mathrm{X}$ initiate a business transaction and the talk is about what is on offer, what exactly will be bought by $\mathrm{R}$, and how business is these days. This topic ends when $\mathrm{X}$ mentions the fact that the shrimps he uses come from his home town; R picks this up and asks in line 11 where X's home town is. This initiates a second topic: the migration trajectory of $\mathrm{X}$ and his knowledge of Putonghua. This topic shifts again in line 30 when $\mathrm{R}$ inquires about the comprehensibility of the speech of other immigrants in the area. The topical shifts correlate with the accent shifts. They latter also correlate with shifts in 'footing': X speaks differently and as a different person in each of the units. In the first unit, his role can best be described as that of a dumpling seller (a clear commercial identity), and stylistically he talks in a slow and neutral tone. In the second topical unit he speaks as an immigrant who comes from the South and has acquired Putonghua at school; stylistically, he appears more excited and enthusiastic. The shift to the topic of the other, more recent, immigrants in the area triggers again another role. He now aligns with $\mathrm{R}$ and appears to define 
himself as an inhabitant of the local Beijing neighbourhood. The migrant identity has been replaced by a local identity, and he expresses a sense of belonging in and entitlement to a place in an engaged and enthusiastic style. He is from an earlier generation of migrants and in contrast with newer immigrants, he is a local man.

The shifts in accents thus come in a package in which topic and role or identity correlate with accent and style. And orientations to space shoot through these packages. In the first unit, the space is neutral: it is a commercial transactional space in which $\mathrm{R}$ and $\mathrm{X}$ have clear roles. In the second unit, the space is that of the South versus Beijing, or the periphery versus the centre, and in the third unit the space is the particular area in Beijing. Spatial orientations frame the interaction, and shifts in such orientations again correlate with the other shifts we already mentioned. Let us try to summarize these packaged shifts in X's speech in a table.

Table 1: Summary of the shifts

\begin{tabular}{|l|l|l|l|l|}
\hline & \multicolumn{1}{|c|}{ Space } & \multicolumn{1}{|c|}{ Accent } & \multicolumn{1}{c|}{ Style } & \multicolumn{1}{|c|}{ Identity } \\
\hline Unit 1 (1-11) & Commercial & Putonghua, & neutral & Dumpling seller \\
& & Beijing accent & & \\
\hline Unit 2 (12-31) & The South and & Southern accent, & Engaged, & Immigrant from \\
& Beijing & Beijing accent & enthusiastic & the South \\
\hline Unit 3 (32-38) & Neighbourhood & Putonghua & engaged & Local resident \\
\hline
\end{tabular}

\subsection{Micro-variation}


The shifts we have seen in the example above are microscopic; they are shifts within one language, shifts in accents that are often only perceivable and distinct to insiders. Their distribution and correlation with other discourse features - topic, style, identity - however, and the correlation we see with particular spatial orientations, show that they provide rich indexical meanings to such insiders, who pick up the shifts and project meanings onto them. In the context of migration, accents - always a plural phenomenon - become very much part of the speech repertoires of people, and they reflect the spatial and social mobility that is a central feature of the experience of migration. ${ }^{7}$ They also become part of indexical repertoires, as accents 'give off' rich meanings about who one is and how one talks. Accents betray life trajectories and in a real social world, where people have mental maps and images of reality, such trajectories are meaningful: spaces are never neutral, as we said earlier, they are always someone's space and always contain orders of indexicality that provide frames for inferring social meanings. X's attempted Beijing accent, consequently, has a very different indexical value in Beijing than in his home town in the South. In both places, the accent produces different images of identity, different interactional orders and different effects on interlocutors. Indexical judgments are primarily local, and when indexical elements move through space, they change value and meaning.

In the context of globalization, consequently, and perhaps paradoxically, analytic attention should go to micro-variation. Increased mobility of people means increased mobility across markets of accents and speech varieties. And what works well in one place can backfire elsewhere. This, no doubt, has implications for the study of language contact. Often, what comes into contact is not languages but regionally (and hence socially, culturally, politically) marked varieties. As we have seen in the example above, the result of such contacts is a layered, multi-accented repertoire that can be mobilised by speakers to produce particular meanings, but can also be mobilised by their interlocutors to ascribe particular 
meanings to them. If we go back to our Nigerian woman for a moment: the heavily accented variety of vernacular Dutch she masters can, for her, be an index of successful integration into the host society; for the schoolteacher, however, or for the welfare worker or local politician, that same accent can index a lack of integration, even a resistance to integration - exactly the opposite.

\section{Conclusion: the unfinished story}

The study of language and space requires a new conceptual apparatus and vocabulary, one in which mobility is central and in which effects of mobility on repertoires and interactional practices can be addressed in their full complexity. Language is traditionally seen as something that anchors people in a local context: it is described as something that belongs to a

particular environment, is locked into local meanings and interactional dynamics. This insight is too important to be dismissed, and research on it has yielded important results. But it is a partial view, for language is also something translocal, it moves along with people across space and time, and it is being deployed locally in ways that reveal the translocal histories of the speaker's resources. Language is not just a tool for the construction of locality, it is also a tool for mobility.

This assumption moves several theoretical issues to the forefront. The effect on concepts such as 'speech community' should be evident (Rampton 1998): in a context of mobility, the connection between a speech community and a set of established, and shared, forms of knowledge of languages and language norms must be questioned. The one who speaks may belong to the same speech community than the one who listens, but only temporarily and without the shared understandings that we assume with members of a speech community, traditionally defined. This, then, locks into another issue: we need to have a 
closer look at the dialogical nature of social interactions as foundations for sociolinguistic research. When common ground between interlocutors can no longer be taken for granted, it is the interactional dynamics and the uptake of each other's words that will inform us about the sociolinguistic contexts of interactions. A fully developed interactional sociolinguistics is therefore something of a priority.

Another issue that awaits focused attention is that of function. Hymes (1996) already warned against the lack of theoretical concern for language functions, observing that the same language form may (and does) have very different functions, depending on where, how and why it is used, and how it fits into speakers' repertoires. This functional relativity is of crucial importance for understanding processes of mobility and language (Blommaert 2003). As repeatedly mentioned earlier, what works well in one place may not work at all elsewhere; highly articulate people in one place may be very inarticulate in other places. Spatial trajectories are also trajectories that affect the function and value of linguistic resources; examining this is a critical task for a sociolinguistics of mobility. All of this, and much more, will be on the agenda of the current and future generations of scholars. We have only begun to spot the challenges, and some we have been able to identify. But the story is, as yet, very much unfinished. 


\section{Notes}

1. In the opening chapter of his Age of Empire, Eric Hobsbawm asks how the world of the 1880 s could be compared with that of the 1790s; his answer is: "[i]n the first place, it was now genuinely global" (Hobsbawm 1987: 13). In effect, the $19^{\text {th }}$ century was the era of globalization, and Hobsbawm actually uses the term globalization for the processes of capitalist expansion in the $19^{\text {th }}$ century (1987: $\left.14 n\right)$.

2. Hobsbawm's oeuvre is again instructive on this point. What we see, in effect, is how every step in the development of modern capitalism was accompanied by political transitions - from oligarchic to democratic states - and by changes in the educational and communication infrastructure of societies that underwent such political and economic transformations. Mass politics (an effect of the labour movement, in turn an effect of the growth of industrial capitalism) required mass media. Globalised business required globalised communication systems such as the telegraph. Observers from each period noted and commented upon such changes as fundamental, deep and lasting changes in society.

3. We must note here the very restricted gaze of such studies. The typical 'host' society since the 1970 s is not a Late Modern West-European state but a third-world country adjacent to another third-world country torn by civil war or by natural disaster. To give one illustration: during the genocide in Rwanda in 1994, an estimated 700.000 Rwandan people entered Tanzania. The refugee camp where most of them were harboured was for all practical purposes the second largest 'city' in the country.

4. The observations in this and the next subsection are the result of fieldwork carried out by Jan Blommaert and associates in 2004 in migrant neighbourhoods in Ghent (Blommaert, Collins \& Slembrouck 2005a, 2005b) and in 2006-2007 in a similar 
neighbourhood in Berchem, Antwerp. The latter neighbourhood is Jan Blommaert's home neighbourhood.

5. Turkish, Arabic, Spanish, Portuguese, Russian and Chinese, on the other hand, would occur in the multilingual flyers of welfare or socio-cultural organizations in the neighbourhood. Blommaert, Creve \& Willaert (2006) examined processes of linguistic disqualification in a Dutch immersion class in Antwerp. It appeared that teachers often did not even know the linguistic repertoires of their pupils. The attitude was that only one language counted as a language: Dutch.

6. Fieldwork was conducted by Jie Kathy Dong. Transcription conventions:

¿', (underline) stress

'=' interruption or next utterance following immediately

' \{\} ' transcriber's comment

'* *' segment quieter than surrounding talk, or weaker than the rest of the sentence '( )' omitted part in the utterance

Bold face represents the shifts among the accents: Beijing accent - provincial accent Putonghua - Beijing accent - Putonghua.

7. Similar phenomena, also revealing the close connections between spatial orientations and packaged micro-shifts, were described in Maryns \& Blommaert (2001) and Blommaert (2005, chapter 8). Attention to phonetic detail - the usual clue to microvariation - is also strongly emphasized by Rampton (2006), whose analyses of multiethnic British classrooms reveal very similar patterns of salience for microscopic accent differences. 


\section{References}

Agha, Asif 2007 Language and Social Relations. Cambridge: Cambridge University Press.

Appadurai, Arjun 1996 Modernity at Large. Minneapolis: University of Minnesota Press.

Blommaert, Jan 2003 Commentary: A sociolinguistics of globalization. Journal of Sociolinguistics 7/4: 607-623.

Blommaert, Jan 2005 Discourse: A Critical Introduction. Cambridge: Cambridge University Press.

Blommaert, Jan 2006 From fieldnotes to grammar: Artefactual ideologies and the textual production of languages in Africa. In Giandomenico Sica (ed.) Open Problems in Linguistics and Lexicography: 13-59. Milan: Polimetrica

Blommaert, Jan 2007 Sociolinguistic scales. Intercultural Pragmatics 4/1: 1-19.

Blommaert, Jan, Kristel Beyens, Henk Meert, Sarah Hillewaert, Kristof Verfaillie, Karen Stuyck \& Anke Dewilde 2005 Grenzen aan de Solidariteit: Formele en informele patronen van solidariteit in het domein van migratie, huisvesting en veiligheid. Brussel: Federaal Wetenschapsbeleid \& Ghent: Academia Press 
Blommaert, Jan, James Collins \& Stef Slembrouck 2005a Spaces of Multilingualism. Language and Communication 25/3: 197-216.

Blommaert, Jan, James Collins \& Stef Slembrouck 2005b Polycentricity and interaction regimes in 'global neighborhoods'. Ethnography 6/2: 205-235.

Blommaert, Jan, Lies Creve \& Evita Willaert 2006 On being declared illiterate: Language-ideological disqualification in Dutch classes for immigrants in Belgium. Language and Communication 26: 34-54.

Britain, David \& Jenny Cheshire (eds.) 2003 Social Dialectology: In Honour of Peter Trudgill. Amsterdam: John Benjamins

Clyne, Michael 2003 Dynamics of Language Contact. Cambridge: Cambridge University Press.

Collins, James 2007 Migration and Multilingualism: Implications for Linguistic Anthropology and Education Research. London, Ghent, Albany: Working Papers in Urban Language and Literacies 47.

Collins, James \& Stef Slembrouck 2007 Goffman and Globalization: Participation frames and the spatial and temporal scaling of migration-related multilingualism. London: Ghent, Albany: Working Papers in Urban Language and Literacies 46. 
Extra, Guus \& Ludo verhoeven (eds.)

1998 Bilingualism and Migration. Berlin:

Mouton de Gruyter

1982 Discourse Strategies. Cambridge: Cambridge University Press.

2003 Globalization, the new economy, and the commodification of language and identity. Journal of Sociolinguistics 7/4: 473-492

Hobsbawm, Eric 1987 The Age of Empire: 1875-1914. London: Abacus

Hymes, Dell 1996 Ethnography, Linguistics, Narrative Inequality: Toward an Understanding of Voice. London: Taylor \& Francis.

Irvine, Judith 2001 The family romance of colonial linguistics: gender and family in nineteenth-century representations of African languages. In Susan Gal \& Kathryn Woolard (eds.) Languages and Publics: The Making of Authority: 30-45. Manchester: StJerome.

Jacquemet, Marco 2005 Transidiomatic Practices: Language and power in the age of globalization. Language and Communication 25/3: 257-277.

Kress, Gunther \& Theo van Leeuwen

1996 Reading Images: The Grammar of Virtual Design. London: Routledge.

Labov, William 1966 The Social Stratification of English in New York City.

Washington DC: Center for Applied Linguistics 
Labov, William 1972 Sociolinguistic Patterns. Philadelphia: University of Pennsylvania Press.

Maryns, Katrijn \& Jan Blommaert 2001 Stylistic and thematic shifting as a narrative resource: Assessing asylum seekers' repertoires. Multilingua 20/1: 61-84.

Pennycook, Alastair 2007 Global Englishes and Transcultural Flows. London: Routledge.

Rampton, Ben 1998 Speech community. In Jef Verschueren, Jan-Ola Östman, Jan Blommaert \& Chris Bulcaen (eds.) Handbook of Pragmatics 1998: 1-30. Amsterdam: John Benjamins.

Rampton, Ben 2006 Language in late Modernity. Cambridge: Cambridge University Press.

Silverstein, Michael 2003 Indexical order and the dialectics of sociolinguistic life. Language and Communication 23: 193-229.

Silverstein, Michael 2006 Pragmatic Indexing. In Keith Brown (ed.) Encyclopaedia of Language and Linguistics, $2^{\text {nd }}$ Edition, vol. 6: 14-17. Amsterdam: Elsevier.

Wallerstein, Immanuel 2004 World-Systems Analysis: An Introduction. Durham NC: Duke University Press. 